without being all of that process.

From the developmental point of view, eye movements observed in this study operate equally for both children and adults, although they appear to be correlated more strongly with veridical perception in adults. Indeed, the only ambiguity in these data is for the children, and that concerns the movement of the eyes in the direction of the right field and their failure to perceive the distinguishing feature in the right field. Although this tendency is not significant, there is some evidence in the literature (Dyer \& Harcum, 1961) to suggest that second-grade children tend to fixate toward the right portion of the visual field. These authors have interpreted their findings as suggesting that, for this developmental period, recency effects (the last element perceived in a series of elements) are stronger than primacy effects, which tend to favor the left portion of a series of elements exposed horizontally. Failure to perceive the elements on the right even when initial eye movements are directed there, as revealed in this study with children, may reflect the continued confusion of this direction and scanning tendencies learned during reading which direct eye movements from left to right.

\section{REFERENCES}

ABELSON, R. B. The facilitation of visual perceptual learning by saccadic eye movements. Unpublished doctoral dissertation, University of Michigan, 1963.

BRYDEN, M. P. The role of post exposural eye movements in tachistoscopic perception. Journal of Experimental Psychology, 1961, $66,568-571$.

CROVITZ, H., \& DAVES, W. Tendencies to eye movements and perceptual accuracy. Journal of Experimental Psychology, 1962, 63, 495-498.

DYER, W. D., \& HARCUM, E. R. Visual perception of binary patterns by preschool children and by school children. Journal of Educational Psychology, 1961, 52, 161-165.

HEBB, D. O. The organization of behavior. New York: Wiley, 1949.

MANDES, E. A developmental study of the relation between visual field accuracy and eye movement directionality. Unpublished doctoral dissertation, George Washington University, 1966.

MANDES, E., \& GHENT, L. The effect of stimulus orientation on the recognition of geometric forms in adults. Paper presented at the meeting of the American Psychological Association, September 1963.

SCOTT, D. N. An annotated bibliography of research on eye movements published during the period 1932-1963. Toronto: Defense Research Board, 1962.

SPERLING, G. The information available in brief visual presentations. Psychological Monographs, 1960, 74, 1-29.

SPERLING, G. A model for visual memory tasks. Human Factors, 1963, 5, 19-31.

SPERLING, G. Successive approximations to a model for short-term memory. Acta Psychologica, 1967, 27, 285-292.

NOTES

1. This research was supported by a USPHS

predoctoral fellowship, No. 1-F1-MH21,450$01 \mathrm{Al}$, awarded to the author during 1964-65, and also by an NIMH grant, No. 04109, awarded to Dr. Lila Ghent Braine. This article is based upon a dissertation submitted in partial fulfillment of the requirements for the $\mathrm{PhD}$

\title{
Response latency as a function of list length
} in paired-associate learning ${ }^{1}$

JOHN CERASO, LEONARD BADER, and MARSHALL SIL VERSTEIN, Institute for Cognitive Studies, Rutgers, The State University, Newark, N.J. 07102

This study investigated the degree to which a scanning mechanism might occur in paired-associate recall. $A$ further question was whether or not scanning might occur in the early phases of learning but then drop out with overlearning. The experiment involved observing the latency of responses at recall when length of list 18 or 16 pairs) and degree of practice were the independent variables. An attempt was made to control for the confounding variable of differential learning that occurs when lists of different lengths are involved. The corrected data presented evidence for scanning at the early phase of learning (i.e., faster recall in the shorter list) and evidence that scanning dropped out with verlearning.

Two possible kinds of recall processes can be logically distinguished in paired-associate recall. One is the recognition or identification of the stimulus term, the other is the retrieval of the response term. Either of these types of recall could occur via a sequential memory search. In recognition, the stimulus term presented to $S$ could be compared to the stored representatives of the stimulus terms of the list, one by one, until a match is found. Again, once the stimulus term has been identified, there could be a sequential search of the response alternatives until the appropriate one is found.

Sternberg (1966) has presented evidence for a sequential process in a recognition task, and so one might expect a similar finding in paired associates. Failure to find such evidence would argue against sequential processing for both recognition and retrieval. In the present experiment, as in the Sternberg experiment, the independent variable is length of list, the assumption being that sequential processes are revealed by longer response latencies in longer lists.

A second thought that determined the design of the present experiment was that search processes might characterize the early stages of learning but might be degree at George Washington University. The author wishes to thank Dr. Braine for her invaluable help with all phases of this research, and also the principal and faculty of St. Jane de Chantal School, Bethesda, Maryland, for their cooperation in providing me with Ss. supplanted by other mechanisms as practice continues. Comments by Ss during PA learning often suggest deliberate learning strategies (the use of mnemonics, etc.) during the early portions of learning, giving way to more automatic recall with overlearning. Perhaps search processes are associated only with the earlier, more deliberate phase of learning.

The present experiment, then, provided for the observation of response latencies during recall for lists varying in length and varying in degree of practice.

\section{METHOD}

A list of 16 nonsense-syllable four-letter monosyllabic noun pairs was constructed and was used as the long, or 16-item, list. The stimuli were taken from the Archer (1960) list and were from 28 to 38 in association value. The responses were from the Thorndike-Lorge word count (1944) with $\mathrm{G}$ frequencies from 2 to 25 .

These 16 pairs were split into two subsets of eight pairs each. The mean associative value of the nonsense syllables was the same in both subsets, as was the mean frequency value of the words. Only one of these subsets was used as the list for the short or $8 \mathrm{~L}$ group. After the experiment was completed, we looked at the number of items recalled from each of these subsets. In the 16-pair list, there were a total of 262 items recalled in all conditions. Of these, 132 were from the pairs used in the short list and 130 were from the pairs not used. It would seem, then, that, as items, the long and short list pairs were quite comparable.

Slides of the material were prepared and were projected on a wall about $6 \mathrm{ft}$ in front of $S$ by a Kodak Carousel slide projector. During the recall trials, presentation of the stimulus started a clock, and the S's response activated a throat microphone which stopped the clock so that $O$ could record the latency of the response.

\section{PROCEDURE}

The pairs were learned by the anticipation method, with the slides shown at a 3-sec presentation rate. There were two presentation orders for the lists, with a 6-sec intertrial interval. At the conclusion of the last learning trial, a recall trial was given where $\mathrm{S}$ was presented with each stimulus item and where S's response and 
Table 1

Mean Response Latency (in Seconds) Based on All Responses

\begin{tabular}{|c|c|c|c|c|c|c|c|}
\hline & & \multicolumn{6}{|c|}{ Number of Practice Trials } \\
\hline & & \multicolumn{2}{|c|}{2} & \multicolumn{2}{|c|}{4} & \multicolumn{2}{|c|}{8.} \\
\hline & & $\overline{\mathbf{x}}$ & SD & $\overline{\mathbf{x}}$ & SD & $\overline{\mathrm{X}}$ & SD \\
\hline Length & 8 & 3.04 & 1.58 & 2.75 & 1.17 & 2.28 & 1.09 \\
\hline of List & 16 & 3.74 & 1.67 & 2.52 & .66 & 3.07 & 1.31 \\
\hline
\end{tabular}

Table 2

Mean Number and Percent of Items Correctly Recalled

\begin{tabular}{|c|c|c|c|c|c|c|c|}
\hline & & \multicolumn{6}{|c|}{ Number of Practice Trials } \\
\hline & & \multicolumn{2}{|c|}{2} & \multicolumn{2}{|c|}{4} & \multicolumn{2}{|c|}{8} \\
\hline & & Number & Percent & Number & Percent & Number & Percent \\
\hline Length & 8 & 3.25 & 40 & 4.58 & 57 & 6.5 & 81 \\
\hline of List & 16 & 3.42 & 21 & 7.25 & 45 & 11.08 & 69 \\
\hline
\end{tabular}

Table 3

Mean Response Latency (in Seconds) Based on Fastest 8-L Response, Two Fastest 16-L Responses from Each S

\begin{tabular}{|c|c|c|c|c|c|c|c|}
\hline & & \multicolumn{6}{|c|}{ Number of Practice Trials } \\
\hline & & \multicolumn{2}{|c|}{2} & \multicolumn{2}{|c|}{4} & \multicolumn{2}{|c|}{8} \\
\hline & & $\overline{\mathbf{x}}$ & SD & $\overline{\mathrm{X}}$ & $\mathrm{SD}$ & $\overline{\mathrm{X}}$ & SD \\
\hline Length & $\begin{array}{r}8 \\
16\end{array}$ & 1.67 & .68 & 1.55 & .99 & 1.15 & .25 \\
\hline & & 2.97 & 2.03 & 1.43 & .26 & 1.27 & .33 \\
\hline
\end{tabular}

its latency were recorded. If $S$ did not respond within $15 \mathrm{sec}$, he would be given a ready signal and the next stimulus would be shown. The recall trial was given after two, four, or eight presentation trials and each $S$ served in only one condition.

\section{SUBJECTS}

With two lengths of list ( 8 or 16 pairs) and three degrees of practice $(2,4$, or 8 trials), there were six groups. Twelve Ss were used in each group for a total of 72 Ss. They were recruited from the campus at Rutgers-Newark, and were randomly placed in the various conditions.

\section{RESULTS}

The mean latency of correct responses was obtained for each $S$; these, in turn, were averaged to yield a mean for each group. These means and their standard deviations are given in Table 1. An analysis of variance of this data resulted in significant $F$ ratios for both main effects (length of list and degree of practice), as well as for the interaction term. Insofar as the practice effect is concerned, the dala provide evidence for increased speed of response with increased practice. There is a problem, however, in interpreting the length-of-list result (and the interaction), since there could be confounding related to the fact that the lists are learned at different rates. Table 2 shows the number and percentage of items recalled in the various conditions. Note that at each level of practice, proportionally fewer items are recalled in the long list. This leads to a problem when comparing long- and short-list latencies. Imagine that the items of each list can be ranked in terms of difficulty, so that some would be learned 16-list items, we hoped to solve the problem of comparing items of different degrees of difficulty, since in both cases we are dealing with the top $12.5 \%$ of the items. Also, dealing with the fastest responses should tend to involve the easiest and first-learned items, so that degree of practice might be more comparable for long- and short-list items.

An analysis of variance performed on the data of Table 3 again shows a significant practice effect, $F(2,66)=9.44$, $p<.01$; a significant effect of list length, $F(1,66)=4.08, p<.05$; and a significant interaction between the two, $\mathrm{F}(2,66)=4.11, \mathrm{p}<.05$. The interaction is accounted for by the fact that the latency difference between the long and the short list is significant only for the two-practice-trial condition, $F(1,66)=12.09, p<.01$, while the $F$ ratios for latency differences at four and eight practice trials are both less than one. Thus, for the items we have chosen to examine, it appears that a latency difference for short and long list recall appears only in the early trials and then disappears with further practice.

\section{DISCUSSION}

The data presented are consistent with a search model of recall, but only for the earliest phase of learning. Of course, the data do not tell us whether this difference in response latency occurs because there are more stimulus items to scan, because there are more response items to scan, or because of some other mechanism that has nothing to do with scanning. One could imagine, for example, that early stages of learning are characterized by redintegration of the response item via mnemonic aids. If for some reason less efficient mnemonics are developed in the longer list, then this could account for the latency difference.

Whatever the explanation is, however, the data support the impression that early and late phases of learning are different and that recall early and late in learning may involve different mechanisms. Further analytic investigatiơn is obviously necessary to disentangle the complex affair known as simple associative pairing.

\section{REFERENCES}

ARCHER, E. J. A re-evaluation of the meaningfulness of all possible CVC trigrams. Psychological Monographs, 1960, 74(10, Whole No. 497).

STERNBERG, S. High-speed scanning in human memory. Science, 1966, 153, 652-654.

THORNDIKE, E. L. \& LORGE, I. The teachers word book of 30,000 words. New York: Bureau of Publications, Teachers College, Columbia University, 1944. NOTE

1. This research was supported by United States Public Health Service Grant MH 14195. 